Article

\title{
Integrated Social Housing and Health Care for Homeless and Marginally-Housed Individuals: A Study of the Housing and Homelessness Steering Committee in Ontario, Canada
}

\author{
Kristy Buccieri \\ Department of Sociology, Trent University, 1600 W Bank Dr, Peterborough, ON K9J 0G2, Canada; \\ kristybuccieri@trentu.ca; Tel.: +1-705-748-1011 \\ Academic Editor: Jerry D. Marx \\ Received: 24 November 2015; Accepted: 24 March 2016; Published: 30 March 2016
}

\begin{abstract}
Homelessness is a complex social issue that requires a coordinated systems approach. In recent years, Canada has seen an emergence of integrated care, the joining of health care and social care, to address the needs of homeless persons. This article documents the findings of open-ended interviews with eleven members of the central east Ontario Housing and Homelessness Framework Steering Committee, comprised of service managers and the Local Health Integration Network. As the system planners for social housing and health care, respectively, members of the group work together to align system approaches for homeless persons. Research by this group identified three challenges of collaborating - their different histories and legislation, varied accountability structures, and differing roles and responsibilities within the central east region of Ontario. The study findings indicate that developing a joint document to guide the work was a process through which members began to work through these differences.
\end{abstract}

Keywords: health; homelessness; integrated care; service managers; social housing; Canada

\section{Introduction}

In the fall of 2014, the central-east region of Ontario began a ground-breaking initiative that brought municipal service managers from four regions together with the local health system planner-the Central East Local Health Integration Network (CE-LHIN)—to form a joint ten-year Housing and Homelessness Steering Committee. This undertaking is an innovative community-based approach to integrated care for homeless and marginally-housed individuals. While integrated care, the joining of health care and social care, is well-documented in the United Kingdom [1,2], it remains a relatively new approach in Canada and across North America. This article details the findings of an ethnographic study of the Housing and Homelessness Steering Committee from the central-east region of Ontario, which comprises approximately 882,000 people and is positioned to the immediate northeast of Toronto. Through this Steering Committee, members jointly attempt to design social housing and health-based programs and initiatives in a coordinated manner for homeless and marginally-housed community members.

The Steering Committee provides an opportunity to study an integrated care initiative as it forms and evolves over time. At the time of the research, conducted in the spring and summer of 2015, the Steering Committee had been meeting every two months for approximately one year. In that time, they developed a guiding document that outlined the committee's purpose, strategic aim, member roles, guiding principles, and terms of reference. The creation of this document was an important output of the committee, as it represented the first time the municipal service managers and the CE-LHIN had formally worked together to address issues of housing, homelessness, and health for 
community members living in the central east region of Ontario. As the system planners, funders, and administrators for housing and homelessness programs in their communities, representatives of four municipal service managers came together in person and on paper with representatives from the CE-LHIN, the system planners and funders for local health initiatives. This jointly-created document marked a critical moment; it provided tangible support for-and a commitment to-providing integrated care for homeless and marginally-housed individuals within these communities (see Figure 1).

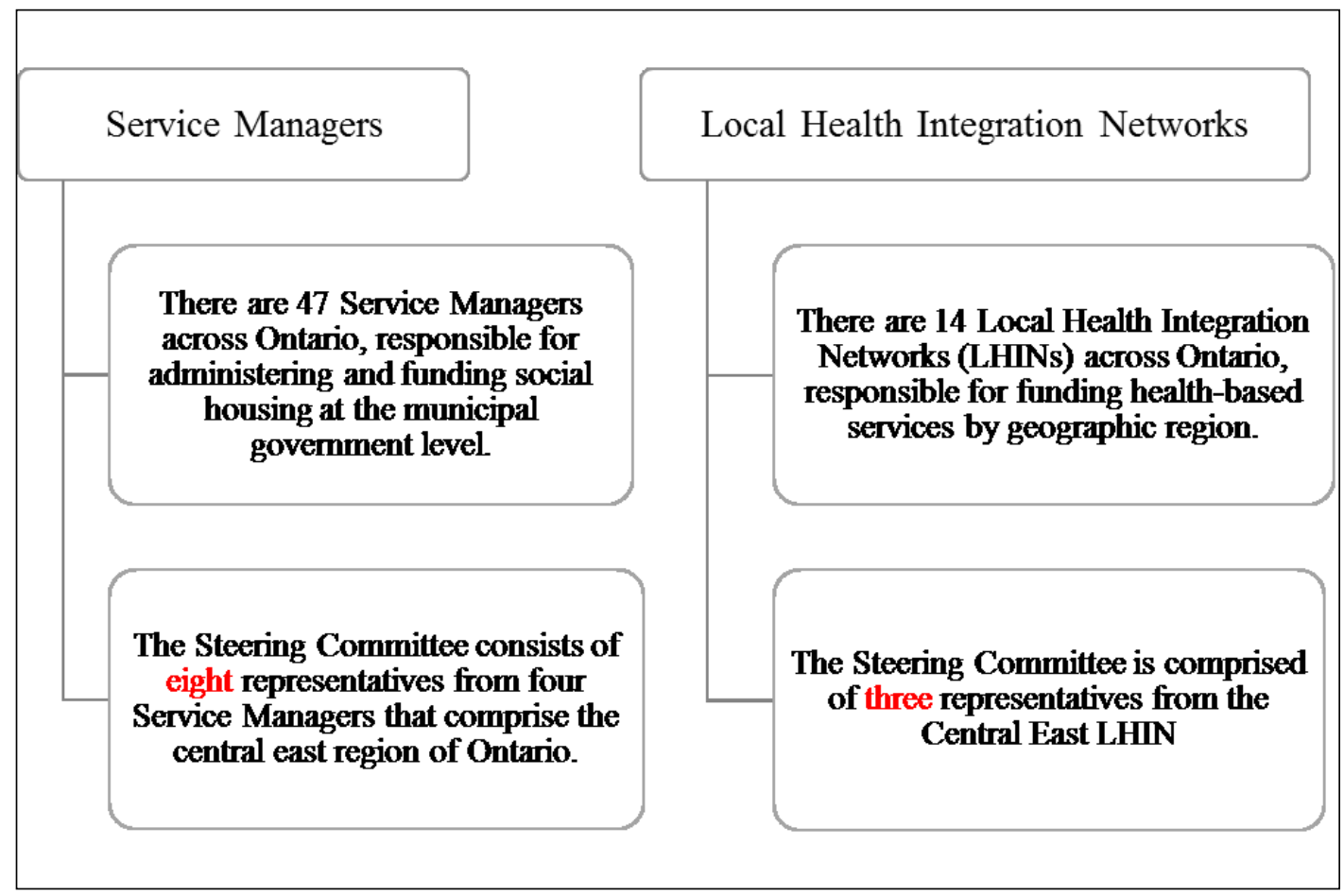

Figure 1. Overview of the Steering Committee members, including representatives from four municipal service managers and the Central East LHIN.

The development of this group is important, not only because it provides documented evidence for integrated care, but because it brings together individuals who are working under different provincial ministries, funded through different initiatives, and governed through different policies and pieces of legislation. Until this committee began, representatives from the municipal service managers and the CE-LHIN had never worked directly together. The regions in this study all experience a demand for affordable housing that outweighs the supply. For instance, in the respective regions: less than $1 \%$ of new housing stock built between 2000-2009 was rental [3], rental housing is described as limited and not affordable to low-income households [4], tenants comprise $19 \%$ of households but only $5 \%$ of new housing stock is rental [5], and over 1500 applicants are on the social housing waiting list [6]. The formation of the Steering Committee is an attempt to collectively address the issue of social housing and to align funding efforts with the CE-LHIN.

In this article, I begin by providing an overview of the literature on homelessness in Canada, with a particular focus on Ontario, and discuss the methodology of the study. Subsequently, I detail the evolution of municipal service managers and the CE-LHIN and examine the three main challenges that members identified in working together-their differing histories and legislation, varied accountability structures, and different orientations toward responsibilities and roles in the central east region of Ontario. I conclude the article with a discussion of how the members jointly created a document to lead their work, a process they noted allowed them to identify and begin to work through these 
three challenges. The discussion is intended to inform the efforts of others working collaboratively on integrated care for homelessness and marginally housed individuals.

\section{Homelessness, Health, and Integrated Care in Canada}

The negative effects of homelessness on physical and mental health are well-documented in Canada, for both adults [7,8] and youth [9]. Entry into homelessness is often associated with a sharp decrease in health status [10], with the occurrence of chronic conditions that are caused and/or reinforced by poverty and the street lifestyle [11]. For instance, in one longitudinal study of homeless individuals in the three Canadian cities of Ottawa, Vancouver, and Toronto, researchers found that over $85 \%$ of participants reported having at least one chronic health condition [12]. Among the most frequently reported conditions found in one study of 149 homeless persons in Toronto, were fatigue, coughing up phlegm or blood, shortness of breath, night-sweats, chest pain, unexplained weight loss or gain, lung disease, arthritis, hepatitis A, B, or C, and diabetes, among others [13]. Researchers in Canada have found that homeless individuals are at higher risk of traumatic brain injury than the general public [14,15], report high rates of untreated dental conditions, with low incidents of dental visits [16], and often face challenges obtaining stable and nutritious food sources $[17,18]$. Many homeless individuals report experiencing mental health issues [19], whether clinically diagnosed [12] or a more general sense of loneliness on the street [20]. Substance use is common among homeless individuals in Canada, and in many instances is related to, or complicated by, mental health factors [21,22].

Despite the evidence that shows homeless individuals experience poor physical and mental health outcomes related to living on the street or in unstable conditions, many homeless individuals rate their health as being excellent or very good [13]. In one study from Toronto, Vancouver, and Ottawa, researchers found many homeless and vulnerably-housed participants rated their health as fair or average; here the authors noted that it is important to contextualize these findings with the understanding that participants frame their own health in relation to those of their friends and family who are in similar circumstances [23]. Homeless individuals often do not access preventative medical care services, describing instances of previous health care visits as being dehumanizing and stigmatizing [24]. Forging a chain of trust, particularly within nurse-patient interactions for marginalized populations, is important in creating a welcoming health care setting [25]. Without this trust, feelings of embarrassment and shame have been found to prevent homeless individuals from seeking out medical information, particularly around sexual health issues for young female and transgender youth [26]. The pressing physical and mental health needs of homeless individuals, combined with their low help-seeking behavior, lends support to the placement of accessible services, like public health clinics, in community-based shelters and drop-in centres [27]. However, while many homeless individuals report accessing some form of services [28], research has also found that the institutional cycling of clients through different agencies can contribute to the spread of disease among service users $[29,30]$.

Improving the health and wellness of homeless persons requires a coordinated approach, such that individuals are able to access a range of services and supports without having to cycle through the system in the process. Integrated care involves bringing together health and social supports in a way that supports the client and his/her particular needs at the centre. While integrated care has been defined in different ways, Kodner and Spreeuwenberg offer one definition that is frequently cited. Accordingly, they write:

Integration is a coherent set of methods and models on the funding, administrative, organisational, service delivery and clinical levels designed to create connectivity, alignment and collaboration within and between the cure and care sectors. The goal of these methods and models is to enhance quality of care and quality of life, consumer satisfaction and system efficiency for patients with complex, long-term problems cutting across multiple services, providers and settings. The result of such multi-pronged efforts 
to promote integration for the benefit of these special patient groups is called "integrated care" [31].

For homeless individuals, integrated care may involve the coordination of housing, health care provision, and mental health and/or substance use supports.

One example of the integrated care philosophy for homeless individuals in North America, is the proliferation of the Housing First model, which emerged through the work of Dr. Sam Tsemberis and Pathways to Housing in the United States [32]. Housing First is defined within a Canadian context as being:

...a recovery-oriented approach to homelessness that involves moving people who experience homelessness into independent and permanent housing as quickly as possible, with no preconditions, and then providing them with additional services and supports as needed. The underlying principle of Housing First is that people are more successful in moving forward with their lives if they are first housed [33].

Housing First is an integrated care approach that connects individuals with supportive housing and case workers who provide transitional assistance and a sense of stability, often with a focus on improving their mental health and wellness.

The Housing First model was implemented in the five Canadian cities of Vancouver, Winnipeg, Toronto, Montréal, and Moncton through the "At Home/Chez Soi" study that operated from 2009-2013 [34]. Through this study, a combined total of 2148 individuals were enrolled in different intervention types, with 1158 placed in the Housing First model. The results of the study strongly indicate that homeless and marginally housed individuals benefit from the combination of housing and integrated supports, like health care provision and mental health/substance use supports. It should be noted, however, that while supported as an integrated approach, the implementation of the Housing First model requires that structural issues be addressed, such as the existing shortage of affordable housing in Ontario [35,36].

A body of Canadian research on supportive housing models that combine subsidized or social housing with accessible supports, shows that the integrated approach to service provision is largely effective. Individual studies have shown that housing combined with supports has a positive effect on health [37], improves outcomes for individuals with serious mental illness [38], improves perceived quality of life [39], increases life satisfaction [40], lowers hospital emergency room visits for adults with mental disorders [41], and reduces the number of days individuals report experiencing alcohol problems [42]. Integrated care models, like Housing First, have been found to be of greatest efficacy when they target the most intensive users of services [38], and when they are supported by staff expertise, multi-service partnerships, and strong leadership [43]. However, research on the accuracy of Housing First success predictive models have found them to be largely ineffective at determining who will maintain stable housing [44].

The health of homeless persons is affected by many factors, with housing status and access to supports being among the most important. Addressing the high rates of chronic health conditions, mental health issues, and substance use found amongst homeless populations in Canada requires a broad social lens that accounts for the multiple factors impacting their health and wellness. While research has shown that not all clinicians working with homeless populations report feeling initially prepared to address the impacts of the social determinants of health on their patients [45], Doran, Misa, and Shah write that:

Social determinants of health should be central to mainstream discussions and funding decisions about health care. For many patients, a prescription for housing or food is the most powerful one that a physician could write, with health effects far exceeding those of most medications [46].

Integrated models that take a broader social perspective of health care delivery are becoming more common, as they improve patient outcomes and reduce overall costs of service provision [47]. 
However, even though health care leaders may support these kinds of innovative approaches, the time, funds, and energy required for a relatively small population may not be where they choose to devote their often limited resources [48].

Kodner and Spreeuwenberg note that the effective design and implementation of integrated care may face barriers and bottlenecks in the five interlocking domains of funding, administration, organization, service delivery, and clinical practice [31]. Others, in a collection of essays, have similarly argued that creating integrated care is challenging and must first address issues pertaining to shared budgets between health and care sectors [49,50], the need for strong and informed leadership [51], the creation of (potentially legally binding) documents that guide and frame collaborations [52], and transparency through shared data [53]. Creating strategies that integrate health and social care, while challenging, are particularly important for addressing the complex needs of homeless individuals.

\section{Methodology}

The study design was influenced by institutional ethnography, as developed and informed through the work of Dorothy Smith [54]. The study involved document review such as municipal housing and homelessness plans [3-6], participant observation, and Steering Committee interviews. Institutional ethnography is a sociological approach that takes texts and documents as an entry point into understanding a given problem. The problematic examined in this study was how the service managers and Central East LHIN organized their relations and interactions with one another, around social housing and health system planning. The guiding question was, "What are the key considerations and challenges that arise in developing a ten-year Housing and Homelessness Framework to guide partnerships and collaboration, according to the Central East LHIN staff and service managers?" The Housing and Homelessness Framework Steering Committee meets in person every two months, in rotating locations throughout the central east region of Ontario. As the Principal Investigator, I attended all seven of the meetings that occurred during the research period, as a participant-observer, and took hand-written research notes. Each meeting lasted approximately $2.5 \mathrm{~h}$.

In the summer of 2015, I conducted semi-structured interviews with all members of the Steering Committee, including three representatives from the CE-LHIN, and two representatives from each of the four municipal service managers. The interviews ranged from one to three hours in length. In three of the regions, service manager interviews were conducted in pairs and in one region interviews were conducted with two members separately. The CE-LHIN interview was conducted with three members, although one member was newer to the Steering Committee and observed more than participated in the interview, creating a paired-interview dynamic much like several of the service managers. In each interview, a guide was used to direct questions but the order of questions was sometimes altered to allow for a more conversational flow. Despite sometimes being in different orders, all participants (whether from a service manager or CE-LHIN) were asked the same questions in five general themes pertaining to their employment role and history; policy and funding context in which they worked; creation of the mandated municipal ten-year housing and homelessness plans; involvement in the Housing and Homelessness Framework Steering Committee; and assistance in creating a timeline of key events and documents shaping their work.

This study was reviewed and approved by Trent University's research ethics board. Participants were provided with the questions in advance and each gave written informed consent. The interviews were audio-recorded and transcribed by the principal investigator and a research assistant. All participants were provided with a copy of the written transcript following the interview and were given thirty days to correct or redact any information they wished. While some minor revisions were made, none of the transcripts were significantly altered from their original texts. All interview transcripts were coded by the Principal Investigator according to the five interview question themes noted above. A table was created in which each response was posted and represented alongside those of other members for each question. I utilized a coding method that involved examining the comparative quotes for similarities, differences, and novel information, as described by Kirby, Greaves, 
and Reid [55]. To help protect participant anonymity, quotes are attributed only to a CE-LHIN or service manager participant throughout the article, without identifying details provided.

This study does have limitations that should be noted at the outset. First, the Steering Committee is comprised of a small number of representatives (i.e., eleven). While every participant was included in the study and the findings can be considered representative of this particular committee, it is unknown how their composition may differ from other groups of this nature. Second, the committee is comprised of system planners and does not include those with identified lived experience of homelessness and/or front-line service providers. As a planning table, these voices are not represented in the committee or in this study. Finally, the group is in its infancy and the study can only provide an examination of how it has formed over its first year. A longitudinal study that evaluated its progress and impact at the community-level would be a valuable long-term undertaking.

\section{Health and Social Housing Sector Collaboration: Identifying Key Challenges}

The Homelessness and Housing Framework Steering Committee is comprised of system planners from the Central East Local Health Integration Network and service managers responsible for funding and administering social housing and homelessness programs in their four respective communities. The Steering Committee meets every two months to try and jointly align funding and programming initiatives that affect the health and wellness of homeless and marginally housed individuals. However, despite taking a collective approach to these issues, the members of the Steering Committee are differently positioned based on a number of key factors. Across sectors-whether health or social housing-committee members are governed by their own legislation and are expected to undertake different roles. Further, between and within sectors, accountability and area of responsibility varies. These three factors-legislation, accountability, and roles-are discussed first as factors that align the group members differently, and at times give rise to conflict and/or challenges. In the section that follows, I discuss the measures the committee members have taken to help address and overcome these factors in building a collaborative framework together.

\subsection{Legislative and Historical Differences}

The province of Ontario provides a novel landscape in which to examine integrated care initiatives like the Housing and Homelessness Framework Steering Committee because the LHINs and service managers are both uniquely Ontario-made through their respective legislation and histories. In the interviews, all participants were asked to speak about the legislative contexts in which they work and to outline the historical evolution of their organizations and roles. While the service managers are all governed by the same pieces of legislation, these do not overlap with the LHIN. The misalignment between the guiding legislation was felt by many participants to be an impediment to integrated work between the health and social housing sectors.

Across Ontario, there are fourteen LHINs, each responsible for health system planning and funding in a designated geographic area, as legislated through the Local Health System Integration Act (LHSIA), 2006 [56]. The introduction of the LHINs in Ontario was met with some public skepticism about their longevity and concern around the term "integration" and what it meant for health care providers. One participant stated that, "I think in the beginning people just didn't know what to make of us and couldn't figure out what we were doing" (CE-LHIN 1). Another participant stated:

CE-LHIN 2: I think when we started it, people were like, "Oh, here comes the next-or first-wave really of integration." I have been through a few system integrations but it was always the planning entities in the province, and the LHIN was the necessary move to bring planning and funding accountability into one local body...But we did not know if it would stick through governments...It's been three elections, at least, of provincial government that...it's stuck through. 
Initial public concerns focused on the word "integration" and what it meant for health service providers:

CE-LHIN 2: With the word "integration" in our name and that being a new term, there was a lot of discussion about, "What does that mean? Is that a merger? Amalgamation? Cease our service? What is that?" We spent a lot of our time in [the] early days explaining that, absolutely, that is part of the continuum of integration but partnerships, collaborations, transfers, mergers, amalgamations, stop service are all in the [LHSIA] as a continuum.

While some uncertainty remains, the CE-LHIN participants believed that their work is better understood and appreciated today than it had been previously:

CE-LHIN 1: I think [the public] understand[s] what it means better. There's still some providers that are very frightened by that. I think the fright comes from believing that they're going to lose their service and their jobs. The opportunity that people see now, that perhaps we saw in the beginning, is the opportunity for the people that they serve. So whereas the planning used to be based on the service, it's now based on the person being served and I think now that people see that, it's kind of renewed the interests of some people who were working in the field.

In comparison to the LHINs, service managers have been operational considerably longer and have also changed and evolved over time. The role began with the federal devolution of social housing to provinces in the 1990s and the subsequent download in Ontario to municipal service managers and District Social Services Administration Boards (DSABs) [57]. Initially created under the Social Housing Reform Act (SHRA), 2000 [58], the service manager role was recently amended and is now legislated through the Housing Services Act (HSA), 2011 [59]. The impacts of federal and provincial downloads are still very much felt today by those in service manager roles. According to one service manager representative interviewed for this project, "...back in 2001 when they transferred housing to the service manager-just a box. Here's a box and a handshake, and I'm serious about that" (SM 1). The history of federal devolutions and provincial downloads have greatly shaped the work of social housing administration in Ontario today. This theme emerged in multiple interviews:

SM 2: [The legislation and funding procedures identified within them are] overly complicated, I think at this point. And I think the root of the problem is that the devolution was done too quickly and there wasn't enough consolidation at that point and there wasn't enough faith in municipalities that they could do a good job and that may have been appropriate back in the day. Municipalities were terribly resistant to this [download].

SM 3: It's a very different world since download. There are a lot more procedures, a lot more things written down...certainly there were no service managers, that kind of collaboration between service managers to get things in place. It's a lot more formal and written down, so that hopefully years and years from now, people won't have to go, "Why did that happen?"

SM 4: One of the interesting things about service managers, and our evolution, is when housing portfolio was downloaded there were a ton of people with lots of -20-30 years' - experience in housing delivery, provincial housing delivery program, that ended up in service manager positions across the province...So we rely on that expertise that is now imbedded within the service manager role to help create some information, fill the information gaps that sometimes all these young folk don't have.

The two primary pieces of legislation that guide the work of the LHINs and service managers are separate and distinct. However, while this separation may be expected given these two groups operate within different sectors, the LHSIA (i.e., the legislation that created LHINs) was created after the service manager boundaries had long been established and operational. This lack of coordination-and the 
missed opportunity for alignment-was a source of considerable frustration that was expressed in multiple interviews.

CE-LHIN 1: With the municipal lens, to a certain extent, we're wandering into territory that we don't really understand, as well as there's some of those old wounds from other processes that we weren't involved in that rear their heads in this process.

SM 3: The province created the Consolidated Municipal service managers and the DSABs...So why, when they created the LHINs, didn't they try and align that with the service managers? That was created by the province-the same province-so why didn't they align it? Perhaps if they had aligned it, things would have evolved differently.

SM 2: The geographic boundaries at the province have never been properly addressed. It's a huge project, but the geographic boundaries are used by all ministries and they set up the province in different ways, and there ought to be an approach whereby we always know that we're connected with these five other municipalities, whereas we're not.

The different legislative contexts and historical evolutions of service managers and the LHIN poses a practical challenge to collaborative working relations. For example, the CE-LHIN is also the health system planner for Scarborough, a region of Toronto that is considerably different in geography and population than the other four communities, and as such is not represented on the Steering Committee. An additional challenge is that one of the service manager regions extends beyond the boundaries of the CE-LHIN, causing them to fall within the bounds of two LHINs. The misalignment of provincial boundaries, such that the work of the LHIN does not clearly overlay the work of the service manager communities, is an issue that the Steering Committee members identified in working together on integrated care planning for homeless persons.

\subsection{Accountability Structures}

Service managers and LHINs are bound by different accountability structures, with the service managers guided by their own municipal elected councils and each LHIN reporting to an appointed board of directors. The nature of the accountability - whether elected or appointed-was described as being an important factor in the reporting relations. According to one CE-LHIN interview participant, the service managers are, "...much closer to the political process than we are. They answer to an elected council, whereas we don't. We have an appointed board, so we don't really have those same pressures" (CE-LHIN 1). The evolution of the service manager role in administering and funding social housing, discussed above, serves to shape the relations with the elected officials to whom they report. This was addressed by one CE-LHIN interview participant who stated:

CE-LHIN 2: Our municipal partners have had to deal with downloads...They also are still having conversations with their municipal councils discussing the appropriateness of who delivers what, and we have similar conversations but the "who delivers what" and "who's being asked to deliver what" is very at the forefront of their discussions.

While the service managers all report to elected officials, they are each designed and operate independently from one another. One service manager representative stated:

SM 4: It's a little bit different in every service manager...so it can be different in terms of the reporting. In terms of the broader goals and objectives and the things that we have to do, they're the same because we're falling under the same [legislation]. Just the nuance of council direction and priorities that are set out by those local councils and in terms of the internal arrangement and the reporting, that will be different based on what the infrastructure is within the level of government because we're regional governments. 
The nature of the reporting relationship with regional council members is also different across service manager communities. Whereas one service manager representative described the relationship with council members as, "...more of a neighborly relationship. I can sit down and talk to them, we can go out for lunch, there's a comfortable relaxing environment" (SM 1), another service manager from a different region stated, "...when you talk about relationships I think of individual one-on-one relationships, and council is a body of people" (SM 2).

The nature of the accountability and reporting differs between service managers and the LHIN, with elected officials and appointed boards, respectively, in those roles. When working collaboratively together, these differences in accountability structures can produce challenges related to factors such as political sensitivities, operational timelines, and budgetary considerations. The accountability of each party involved in the Steering Committee was a central consideration in moving the group towards a collaborative framework.

\subsection{Priorities and Roles}

The third identified challenge of collaborating within the Steering Committee was the different nature of the service manager and LHIN roles. Within their individual communities, service managers are responsible for establishing, funding, and administering social housing (among other) programs, while the LHIN serves exclusively in a funding capacity without the administration component. These different functions were noted by several interview participants. According to one service manager representative:

SM 5: There's an interesting kind of dynamic, in my opinion, in that [service managers] are immersed in our community and we have community partners that we're trying to do this work with, but we have a dual role of we are providing service and we are funding service and the LHIN has only the role of funding service. But, at least in this forum we are able to talk funder to funder.

Beyond the different roles, as administrators and/or funders, the Steering Committee members also bring to the table their unique positions and priorities. In particular, the CE-LHIN interest extends broadly across the central east region of Ontario, while service managers are concerned with their individual municipalities. As a planning table, the differently aligned interests of the parties emerged as a notable challenge that needed to be considered and addressed. The difference in priorities was noted by CE-LHIN and service manager interview participants:

CE-LHIN 2: [service manager] interests are most directed to their own. They're less interested in knowing what another municipality has. We're very interested to know how the different municipalities are using similar pots of money. That's not so much their concern, other than sometimes if it's problem solving for them.

SM 4: There's one LHIN and then there's the service managers, which are multiples...And so what we're trying to do is create some more, better balance in the system across the communities but we're still coming at it from a service manager perspective. We're coming at this from our individual service managers and not one-to-one...We're not coming at it as service manager/LHIN. We're coming at it from service managers and LHIN, which must make it very difficult for them because they're the ones trying to do the balance...I think that's an important piece of the structure, that it's 4:1.

Entering into a collaborative Steering Committee with different roles and service area priorities was a challenge that service managers and the CE-LHIN had to collectively address and attempt to overcome.

\section{Working through Key Challenges: Drafting a Guiding Framework Document}

The Steering Committee was formed with the recognition that key challenges existed, stemming from their historical and legislative differences, accountability structures, and varied priorities 
and roles. Members sought to address these challenges through the joint creation of a guiding document. Throughout the first year, the Steering Committee devoted 20 to 30 min at each meeting to collaboratively drafting a guiding principles and terms of reference document that outlined their work together [60]. The final product is an eight-page document that will be reviewed annually and contains sections on the Steering Committee's purpose and strategic aim, member roles, legislative and policy context, guiding principles, terms of reference, and approvals. The process of drafting the document was, itself, not without challenges, as members worked systematically to refine the language within each section.

As an observer, I witnessed this process first-hand in Steering Committee meetings. Led by a CE-LHIN representative, the working document would be projected onto a large screen for all members to see. The group would begin with the first section and members would be asked to read it to themselves. The CE-LHIN member would ask for comments on the section shown and members would offer comments or proposed changes. The group would then discuss the proposed change and decide on whether they wanted to accept it, reject it, or make some alteration. The CE-LHIN member would then live-edit the document on a computer and all members could see the changes being made on the overhead projection. This process would be repeated for every section of the document, often returning to previous sections as new comments or suggestions were made. The document would then be e-mailed to all members to review again on their own time following the meeting. At each subsequent meeting this process would be repeated until the guiding framework document was finalized in April 2015.

In the interviews, committee members variously described the process of drafting the document as, "kind of tedious" (SM 7), "a little painful but not too bad" (SM 2), and "not rushed; something that has been tweaked for quite a while" (SM 6). The most commonly-noted challenge in working collaboratively on this process was that it involved, "a lot of collective wordsmithing" (SM 2) which emerged due to the different working vocabularies and acronyms across the health and social housing sectors. As one SM noted, "There's some people that are extremely literal...and are not comfortable unless the language is very, very clear" (SM 4). Despite the repetitive wordsmithing involved, the process of constructing a shared guiding document provided a tool through which members could begin to identify and work through the challenges of their historical and legislative differences, accountability structures, and varied priorities and roles.

CE-LHIN 2: I'd say the time spent up-front in getting the agreement on guiding principles, and it is a long time, but...it's good time spent. Now we haven't had full fruition of that but I believe that it was good time spent, particularly because these are new partners to one table and we're new. I think we just needed to allow that time. Another learning would be, and again we haven't seen it to fruition but, putting forward a common strategic aim for the group...This is the approach we take and that's an objective, a common goal...a statement we can take out and show people.

It should be noted that the key challenges the group faces are systemic and not easily eradicated through the construction of one document. Rather, the joint framework provided an opportunity to identify the challenges, acknowledge their existence within the context of the group, and allow members an opportunity to begin to address them within their own powers and abilities. In the remainder of this section, I return to the three key challenges and briefly show how members negotiated them within the context of the guiding framework document.

\subsection{Legislative and Historical Differences}

In Ontario, the LHINs and service managers have emerged within different historical and legislative contexts, resulting in misaligned service boundaries within the province. While a joint document created by the Steering Committee could not change the legislation or retroactively align boundaries, the members could acknowledge these issues and agree to consciously work around 
them. For instance, a footnote within the document states that a town in one of the service manager counties, "...will be included in planning under this Framework while being beyond the boundary of the Central East LHIN" [60]. Another note within the document states that, "The Central East LHIN will engage directly with the City of Toronto for collaboration and partnership opportunities for residents of Scarborough. When appropriate, opportunities for collaboration and information sharing across all five service managers within the Central East LHIN will be pursued" [60]. This notation is required as Scarborough, part of the City of Toronto, is geographically within the CE-LHIN but is not part of the Steering Committee for reasons beyond the scope of this article.

One concern raised in drafting the document was the inclusion of the word "integration", given the general early resistance to this term when the LHINs first emerged. In the interviews, one CE-LHIN member shared how antipathy toward the term 'integration' impacted the development of the document.

CE-LHIN 2: ...integration was and is, I would say still, a very foreign term but our municipal partners are more uneasy with the term integration. Similar to how our service providers might have felt in the beginning around the term integration, in understanding it, because we had to spend a lot of time explaining. There was even a suggestion early on at the Steering Committee table that we not use the word integration. We couldn't agree to that but we can define it other ways.

The term integration does appear in the Steering Committee document but, with only one exception, is limited to the name of the LHIN, a description of its mandate, and mention of the Local Health System Integration Act as guiding legislation. The one exception is the inclusion of a continuum of care principle that states, "The LHIN and service managers will work with other key housing, community and health service stakeholders in their communities to ensure services are integrated and provide a continuum of care to meet the varied needs of residents" [60]. While the inclusion of integration in this principle suggests the group has found some consensus to begin to work from, the general lack of the term integration within the document highlights that further work on this issue remains be done.

\subsection{Accountability Structures}

The members of the Steering Committee each report to an external authority, whether an appointed board, as with the CE-LHIN, or an elected council, as with the service managers. In drafting a joint agreement, the members recognized that they were not only speaking on behalf of those at the table but that they represented the interests of others as well. The challenge associated with the accountability structures was the diversity in that as one SM noted there are, "...differing approval processes and different cultures, and so you're bringing all of those together and it's not easy to get sign-off and language that seems to fit everyone well" (sic) (SM 5). The way the Steering Committee attempted to address this challenge in the guiding document was the inclusion of two sections on sponsors and membership accountability.

Sponsors are identified in the document as the Chief Administrative Officers of the Municipality and the Chief Executive Officer of the LHIN or their delegates. These sponsors are there to, "...assist the process as required in obtaining and sustaining support for the process from their respective organizations" [60]. Within the document it further states that sponsors will receive key messages, prepared by the Steering Committee, on a regular basis and following significant events. Under the heading "Membership Accountability", it further states that members will be responsible for liaising with the respective municipal, regional, or provincial leads and organizations, and communicating directly with their sponsors regarding issues, information sharing, and recommendations discussed at the Steering Committee meetings. The final section of the document includes an approval section in which members and their sponsor are required to sign. Although the accountability structures, themselves, have not changed as a result of this framework document, members had the opportunity 
to explain to one another how their reporting works and to gain a deeper understanding of each other's processes.

\subsection{Priorities and Roles}

The Steering Committee brings together members from the CE-LHIN, who fund health care services, and representatives from four service manager regions, who fund and administer social housing programs. The differences in priorities and roles is evident in the guiding document, as considerable space is devoted to explicating the purpose of the Steering Committee and the expectations of its members. The document forefronts this information in its first four sections, a representation of the high priority given to clarifying these issues by the Steering Committee members. For instance, the first section entitled "Purpose" states that the group will, "Collaborate during organizational strategic planning with intent to identify common priorities; undertake collaborative service level planning to improve coordination of services and ability for residents to obtain and then retain tenancy; and identify opportunities to align and maximize new investments and existing funding to address needs in [each] community" [60]. Following this section, the document outlines three strategic aims, the Central East LHIN role, and the service manager role.

Creating the guiding document together also allowed members of the Steering Committee to clearly outline what their expectations were and to establish their own limitations as collaborators. The process served as an extended introduction between members. As one CE-LHIN representative stated in an interview, "We did explain where our limitations were around funding and I think that was really helpful...I think really understanding what you can and can't do is incredibly helpful to the process" (CE-LHIN 1). A service manager similarly stated in an interview that, "We're very fortunate to be able to have these discussions...We don't influence the priorities, I don't believe we do, but I believe we influence how the pie gets distributed based on them being more knowledgeable about what some of the pressures we have [are] and what we're trying to do" (SM 4). One example of this sort of influence that emerged out of the framework discussions was an increased allocation of rent supplements within these regions because as one SM noted, “...we were ready and responsive to [CE-LHIN's] questions as they were making their funding decisions" (SM 2).

The different roles of the CE-LHIN as a system wide planner and service managers as municipal planners initially raised concerns that the Steering Committee table, “...doesn't become another place where the loudest voice gets a share of the pie and that it's not just about the LHIN and their money, but it's about the housing piece as well" (SM 4). The Steering Committee recognized this challenge and attempted to address it within the guiding document by including a statement that reads:

The Steering Committee will adopt a consensus model of decision-making for recommendations/advice. As such, deliberations will seek to build consensus on the most acceptable advice/direction considering the best interests of residents. Where consensus cannot be reached, the Steering Committee will present a summary of the deliberations to their respective Sponsors for input and direction [60].

A footnote within this passage defines consensus as, "general or widespread agreement among all the members of a group" [60]. The consensus model may mean that decisions are not unanimous and some members may be unsatisfied with future decisions. However, a service manager noted, "We're all also pretty reasonable people and so we say as long as there's a rational approach to the allocation of funds, we'll probably all be good with that" (SM 5). This brief discussion of the guiding document is not exhaustive but is meant to demonstrate examples of how members have used the creation of this document to acknowledge and attempt to work through the key challenges they face. 


\section{Conclusions}

Homelessness is a pressing issue in Canada, and other parts of the world, that requires a systems approach. In central east Ontario, a group of service managers and health system planners have formed a collaboration to better coordinate health and housing services for members of their respective communities. This ethnographic study of the group highlighted three key challenges that emerged: historical and legislative differences, varying accountability structures, and different responsibilities and roles. The Steering Committee recognized these challenges and spent a considerable amount of their initial time together drafting a joint guiding framework document that acknowledged these issues and attempted to work through them. The process of jointly creating the principles and terms was described as being just as important as, if not more than, the actual document itself. Working collaboratively on creating the document opened a narrative space at the table for members to deconstruct central aspects of their own work, while learning about those of their partners.

Throughout the interviews, participants clearly identified and reflected on the challenges that emerged through the first year of the Steering Committee. Integrated care remains relatively new in Canada and across North America, with a more developed presence in the United Kingdom [2]. As such, it is foreseeable that issues might arise pertaining to legislative misalignment, differing accountability structures, and a focus on collective versus individual interests. Similar challenges have been noted in the UK, related to coordinating health and social care budgets [49,50], characteristics of individuals who assume leadership roles [51], and sharing data freely between collaborators [53]. Homelessness is a prevalent issue in Canada, and studies have shown that combining health and social care has effective outcomes for physical and mental health [37,38], quality of life [39], life satisfaction [40], and the use of emergency health services [41].

The positive outcomes related to integrated care efforts, like supportive housing combined with health and wellness services, lends support to increased investments in combined health and social care for homeless persons. While challenges may be likely to emerge when parties collaborate across sectors, there is also the possibility for innovative practice to emerge. The literature suggests that integrated care is most effective when targeting the highly-intensive service-users [38], when efforts are supported by expertise, multi-service partnerships, and strong leadership [43], and when collaborations are outlined in documents that hold parties accountable to one another [52]. While the members of the central east Ontario Steering Committee continue to navigate the complex relations that underlie their collaborative system planning work, the year together has brought about key learnings that others can adopt and build upon.

The first key learning is that it is possible to bring stakeholders together, even if they have no established pre-existing relationship. The members of the Steering Committee were brought together based on a shared interest in aligning social housing and health supports, despite not having collaborated before. The second lesson is that challenges, while likely to emerge when working intersectorally, are not insurmountable and may even be beneficial in opening a dialogue. Third, members of a group, such as the Steering Committee discussed here, should devote time to identifying their differences and explaining their roles, expectations, abilities, and limitations to one another even if they share similar positions. Fourth, the creation of a joint document, while potentially time consuming, is a valuable exercise that provides a tangible resource for the group members over the duration of the partnership. The joint document produced by this Steering Committee is publicly available as a model [60], although individual groups are strongly encouraged to adapt it to their own work. Finally, participation in a collaborative group that brings different system planners together can be one step toward improving systemic challenges, if not eradicating them altogether.

In this article, I discussed how challenges emerged in relation to the Steering Committee's work and how the members collectively worked to try to overcome them. The creation of a joint document guiding their work provided a process through which members came to better understand and appreciate one another's language, capabilities, and limitations. Integrated care is increasingly becoming recognized as a valuable system planning approach, particularly for addressing the needs 
of vulnerable individuals. While collaborative approaches like the Steering Committee may pose challenges for members, they also provide the tools for working through them.

Acknowledgments: The research project discussed in this article was funded through a Trent University Canadian Institutes of Health Research Internal Operating Grant (Number 23715 to author). The author would like to thank research assistants Matt Tallon and Amy (Olivia) Sayles, as well as all research participants for their time and contributions to the study. The author would also like to thank three anonymous reviewers for their helpful comments and suggestions.

Conflicts of Interest: The author declares no conflict of interest.

\section{References}

1. Nigel Keohane. A Problem Shared? Essays on the Integration of Health and Social Care. London: The Social Market Foundation, 2015.

2. Public Health Englan. Local Leadership, New Approaches: How New Ways of Working Are Helping to Improve the Health of Local Communities. London: Public Health England, 2015.

3. The Regional Municipality of Durham. At Home in Durham: Durham Region Housing Plan 2014-2024. Whitby: The Regional Municipality of Durham, 2013.

4. City of Kawartha Lakes. Building Strong Communities: Housing and Homelessness Plan 2014-2023. Lindsay: City of Kawartha Lakes, 2013.

5. Northumberland County. Northumberland Housing and Homelessness Plan 2014-2023. Cobourg: Northumberland County, 2013.

6. City of Peterborough. Peterborough: 10-Year Housing and Homelessness Plan 2014-2024. Peterborough: City of Peterborough, 2013.

7. Charles J. Frankish, Stephen W. Hwang, and Darryl Quantz. "Homelessness and health in Canada: Research lessons and priorities." Canadian Journal of Public Health 96 (2005): S23-29. [PubMed]

8. Stephen W. Hwang. "Homelessness and health." Canadian Medical Association Journal 164 (2001): 229-33. [PubMed]

9. Katharine Kelly, and Tullio Caputo. "Health and street/homeless youth." Journal of Health Psychology 12 (2007): 726-36. [PubMed]

10. Alistair Story. "Slopes and cliffs in health inequities: Comparative morbidity of housed and homeless people." The Lancet 382 (2013): S93.

11. Isolde Daiski. "Perspectives of homeless people on their health and health needs priorities." Journal of Advanced Nursing 58 (2007): 273-81. [CrossRef] [PubMed]

12. Stephen Hwang, Tim Aubry, Anita Palepu, Susan Farrell, Rosane Nisenbaum, Anita Hubley, Fran Klodawsky, Evie Gogosis, Elizabeth Hay, Shannon Pidlubny, and et al. "The health and housing in transition study: A longitudinal study of the health of homeless and vulnerably housed adults in three Canadian cities." International Journal of Public Health 56 (2011): 609-23. [CrossRef] [PubMed]

13. Kristy Buccieri, and Stephen Gaetz. Facing FAQs: H1N1 and Homelessness in Toronto. Toronto: Canadian Observatory on Homelessness, 2015.

14. Stephen W. Hwang, Angela Colantonio, Shirley Chiu, George Tolomiczenko, Alex Kiss, Laura Cowan, Donald A. Redelmeier, and Wendy Levinson. "The effect of traumatic brain injury on the health of homeless people." Canadian Medical Association Journal 179 (2008): 779-84. [CrossRef] [PubMed]

15. Jane Topolovec-Vranic, Naomi Ennis, Angela Colantonio, Michael D. Cusimano, Stephen W. Hwang, Pia Kontos, Donna Ouchterlony, and Vicky Stergiopoulos. "Traumatic brain injury among people who are homeless: A systematic review." BMC Public Health 12 (2012): 1059. [CrossRef] [PubMed]

16. Rafael L.F. Figueiredo, Stephen W. Hwang, and Carlos Quiñonez. "Dental health of homeless adults in Toronto, Canada." Journal of Public Health Dentistry 73 (2013): 74-78. [CrossRef] [PubMed]

17. Stephen Gaetz, Valerie Tarasuk, Naomi Dachner, and Sharon Kirkpatrick. "'Managing' homeless youth in Toronto: Mismanaging food access and nutritional well-being." Canadian Revue of Social Policy 58 (2006): 43-61.

18. Valerie Tarasuk, Naomi Dachner, Blake Poland, and Stephen Gaetz. "Food deprivation is integral to the 'hand to mouth' existence of homeless youths in Toronto." Public Health Nutrition 12 (2009): 1437-42. [CrossRef] [PubMed] 
19. Cheryl Forchuk, Rick Csiernik, and Elsabeth Jensen. Homelessness, Housing, and Mental Health: Finding Truths_Creating Change. Toronto: Canadian Scholars' Press Inc., 2011.

20. Ami Rokach. "Private lives in public places: Loneliness of the homeless." Social Indicators Research 72 (2005): 99-114. [CrossRef]

21. Michelle N. Grinman, Shirley Chiu, Donald A. Redelmeier, Wendy Levinson, Alex Kiss, George Tolomiczenko, Laura Cowan, and Stephen W. Hwang. “Drug problems among homeless individuals in Toronto, Canada: Prevalence, drugs of choice, and relation to health status." BMC Public Health 94 (2010): 94. [CrossRef] [PubMed]

22. Maritt Kirst, Tyler Frederick, and Patricia G. Erickson. "Concurrent mental health and substance use problems among street-involved youth." International Journal of Mental Health and Addiction 9 (2011): 543-53. [CrossRef]

23. Anne M. Gadermann, Anita M. Hubley, Lara B. Russell, and Anita Palepu. "Subjective health-related quality of life in homeless and vulnerably housed individuals and its relationship with self-reported physical and mental health status." Social Indicators Research 116 (2014): 341-52. [CrossRef]

24. Chuck K. Wen, Pamela L. Hudak, and Stephen W. Hwang. "Homeless people's perceptions of welcomeness and unwelcomeness in healthcare encounters." Journal of the Society of General Internal Medicine 22 (2007): 1011-17. [CrossRef] [PubMed]

25. Bernadette Pauly. "Close to the street: Nursing practice with people marginalized by homelessness and substance use." In Homelessness and Health in Canada. Edited by Manal Guirguis-Younger, Ryan McNeil and Stephen W. Hwang. Ottawa: University of Ottawa Press, 2014, pp. 211-32.

26. Vanessa Oliver, and Rebecca Cheff. "Sexual health: The role of sexual health services among homeless young women living in Toronto, Canada." Health Promotion Practice 13 (2012): 370-77. [CrossRef] [PubMed]

27. Kristy Buccieri, and Stephen Gaetz. "Ethical vaccine distribution planning for pandemic influenza: Prioritizing homeless and hard-to-reach populations." Public Health Ethics 6 (2013): 185-96. [CrossRef]

28. Stephen R. Poulin, Marcella Maguire, Stephen Metraux, and Dennis P. Culhane. "Service use and costs for persons experiencing chronic homelessness in Philadelphia: A population-based study." Psychiatric Services 61 (2010): 1093-98. [CrossRef] [PubMed]

29. S. Harris Ali. "Tuberculosis, homelessness, and the politics of mobility." Canadian Journal of Urban Research 19 (2010): 80-107.

30. Stephen W. Hwang, Alex Kiss, Minnie M. Ho, Cheryl S. Leung, and Adi V. Gundlapalli. “Infectious disease exposures and contact tracing in homeless shelters." Journal of Health Care for the Poor and Underserved 19 (2008): 1163-67. [CrossRef] [PubMed]

31. Dennis L. Kodner, and Cor Spreeuwenberg. "Integrated care: Meaning, logic, applications, and implications-A discussion paper." International Journal of Integrated Care 2 (2002): e12. [PubMed]

32. Deborah K. Padgett, Benjamin J. Henwood, and Sam J. Tsemberis. Housing First: Ending Homelessness, Transforming Systems and Changing Lives. New York: Oxford University Press, 2016.

33. Stephen Gaetz, Fiona Scott, and Tanya Gulliver. Housing First in Canada: Supporting Communities to End Homelessness. Toronto: Canadian Homelessness Research Network Press, 2013.

34. Paula Goering, Scott Veldhuizen, Aimee Watson, Carol Adair, Brianna Kopp, Eric Latimer, and Tim Aubry. National Final Report: Cross-Site at Home/Chez Soi Project. Calgary: Mental Health Commission of Canada, 2014.

35. Suzanne Zerger, Katherine Francombe Pridham, Jeyagobi Jeyaratnam, Stephen W. Hwang, Patricia O'Campo, Jaipreet Kohli, and Vicky Stergiopoulos. "Understanding housing delays and relocations within the Housing First model." The Journal of Behavioral Health Services \& Research 43 (2016): 38-53. [CrossRef] [PubMed]

36. Suzanne Swanton. "Social Housing Wait Lists and the One-Person Household in Ontario." Master's Thesis, University of Waterloo, Waterloo, ON, Canada, 2011.

37. Natalie Waldbrook. "Exploring opportunities for healthy aging among older persons with a history of homelessness in Toronto, Canada." Social Science \& Medicine 128 (2015): 126-33. [CrossRef] [PubMed]

38. Stephen W. Hwang, and Tom Burns. "Health interventions for people who are homeless." Lancet 384 (2014): 1541-47. [CrossRef] 
39. Michelle Patterson, Akm Moniruzzaman, Anita Palepu, Denise Zabkiewicz, Charles J. Frankish, Michael Krausz, and Julian M. Somers. "Housing first improves subjective quality of life among homeless adults with mental illness: 12-Month findings from a randomized control trial in Vancouver, British Columbia." Social Psychiatry and Psychiatric Epidemiology 48 (2013): 1245-59. [CrossRef] [PubMed]

40. Stephen W. Hwang, Evie Gogosis, Catharine Chambers, James R. Dunn, Jeffrey S. Hoch, and Tim Aubry. "Health status, quality of life, residential stability, substance use, and health care utilization among adults applying to a supportive housing program." Journal of Urban Health: Bulletin of the New York Academy of Medicine 88 (2011): 1076-90. [CrossRef] [PubMed]

41. Angela Russolillo, Michelle Patterson, Lawrence McCandless, Akm Moniruzzaman, and Julian Somers. "Emergency department utilisation among formerly homeless adults with mental disorders after one year of housing first interventions: A randomised controlled trial." International Journal of Housing Policy 14 (2014): 79-97. [CrossRef]

42. Maritt Kirst, Suzanne Zerger, Vachan Misir, Stephen Hwang, and Vicky Stergiopoulos. “The impact of a housing first randomized controlled trial on substance use problems among homeless individuals with mental illness." Drug and Alcohol Dependence 146 (2015): 24-29. [CrossRef] [PubMed]

43. Eric Macnaughton, Ana Stefancic, Geoffrey Nelson, Rachel Caplan, Greg Townley, Tim Aubry, Scott McCullough, Michelle Patterson, Vicky Stergiopoulos, Catherine Vallée, and et al. "Implementing housing first across sites and over time: Later fidelity and implementation evaluation of a pan-Canadian multi-site housing first program for homeless people with mental illness." American Journal of Community Psychology 55 (2015): 279-91. [CrossRef] [PubMed]

44. Jennifer S. Volk, Tim Aubry, Paula Goering, Carol E. Adair, Jino Distasio, Jonathan Jetté, Danielle Nolin, Vicky Stergiopoulos, David L. Streiner, and Sam Tsemberis. “Tenants with additional needs: When housing first does not solve homelessness." Journal of Mental Health 3 (2015): 1-7. [CrossRef] [PubMed]

45. Ryan McNeil, Manal Guirguis-Younger, Laura B. Dilley, Jeffrey Turnbull, and Stephen W. Hwang. "Learning to account for the social determinants of health affecting homeless persons." Medical Education 47 (2013): 485-94. [CrossRef] [PubMed]

46. Kelly M. Doran, Elizabeth J. Misa, and Nirav R. Shah. "Housing as healthcare-New York's boundary-crossing experiment." New England Journal of Medicine 369 (2013): 2374-77. [CrossRef] [PubMed]

47. Rebecca Onie, Paul Farmer, and Heidi Behforouz. "Realigning health with care: Lessons in delivering more with less." Stanford Social Innovation Review 10 (2012): 28-35.

48. Carol Wilkins. "Connecting permanent supportive housing to hear care delivery and payment systems: Opportunities and challenges." American Journal of Psychiatric Rehabilitation 18 (2015): 65-86. [CrossRef]

49. Caroline Abrahams. "Caring for an ageing population." In A Problem Shared? Essays on the Integration of Health and Social Care. Edited by Nigel Keohane. London: The Social Market Foundation, 2015, pp. 26-29.

50. Richard Bowden. "Joining up health and care to meet each person's needs-A provider's perspective to being patient-centred." In A Problem Shared? Essays on the Integration of Health and Social Care. Edited by Nigel Keohane. London: The Social Market Foundation, 2015, pp. 44-47.

51. Jeremy Hughes. "Apart at the seams: The challenge of integrating dementia care." In A Problem Shared? Essays on the Integration of Health and Social Care. Edited by Nigel Keohane. London: The Social Market Foundation, 2015, pp. 21-25.

52. Sir John Oldham. "Collective commissioning." In A Problem Shared? Essays on the Integration of Health and Social Care. Edited by Nigel Keohane. London: The Social Market Foundation, 2015, pp. 34-38.

53. Tim Kelsey. "Unleashing the power of people: Why transparency and participation can transform health and care services." In A Problem Shared? Essays on the Integration of Health and Social Care. Edited by Nigel Keohane. London: The Social Market Foundation, 2015, pp. 39-43.

54. Dorothy Smith. Institutional Ethnography: A Sociology for People. Oxford: AltaMira Press, 2005.

55. Sandra Kirby, Lorraine Greaves, and Colleen Reid. Experience Research Social Change: Methods beyond the Mainstream, 2nd ed. Peterborough: Broadview Press, 2006.

56. Ontario. "Local Health System Integration Act 2006 (ON) c. 4." Available online: http:/ /www.ontario.ca / laws/statute/06104 (accessed on 20 November 2015).

57. Housing Services Corporation. Canada's Social and Affordable Housing Landscape: A Province-to-Province Overview. Toronto: Housing Services Corporation, 2014. 
58. Government of Ontario. "Social Housing Reform Act 2000 (ON) c. 27." Available online: http:/ /www.ont ario.ca/laws/statute/00s27 (accessed on 20 November 2015).

59. Government of Ontario. “Housing Services Act 2011 (ON) c. 6." Available online: http:/ /www.ontario.ca/ laws/statute/11h06 (accessed on 20 November 2015).

60. Kristy Buccieri. Ethnography of the Central East Health, Housing, and Homelessness Steering Committee. Report and Toolkit. Toronto: Homeless Hub, 2015, pp. 44, 45, 48-50.

(C) 2016 by the author; licensee MDPI, Basel, Switzerland. This article is an open access article distributed under the terms and conditions of the Creative Commons by Attribution (CC-BY) license (http:/ / creativecommons.org/licenses/by/4.0/). 